\title{
Os conflitos, barreiras e conquistas das relações de gênero na educação infantil
}

Elsa Santana dos Santos Lopes

Pedagoga, pós-graduada em Coordenação Pedagógica na Escola Básica, mestre em Educação pela Umesp, doutoranda em Educação: currículo pela PUC/SP

E-mail: elsa.lopes@ig.com.br
Resumo: 0 presente trabalho discute o percurso histórico da educação infantil nas principais leis e documentos que orientam a educação brasileira sob a ótica de gênero. Muitos são os conflitos e barreiras da educação infantil, porém, ao longo dos anos várias conquistas foram alcançadas na perspectiva das relações de gênero nessa etapa da educação básica. Oportunizar interações entre os pares nas instituições de atendimento à pequena infância é propiciar formas variadas de compreensão de si, do outro e da realidade. 0 tema ganha relevância na construção de uma educação infantil atenta a relações mais igualitárias na perspectiva de gênero.

Palavras-chave: Educação infantil. Relações de gênero. Formação de educadores. 


\section{CAMINHOS DA EDUCAÇÃO INFANTIL: DA ASSISTÊNCIA À EDUCAÇÃO}

Creche, escola maternal, sala de asilo, escola de tricotar, jardim da infância, pré-escola, pré-primário e educação infantil são alguns nomes que foram dados, ao longo da história, a instituições de educação de crianças pequenas. De acordo com Abramowicz e Wajskop (1999), o nome e a concepção norteadora da prática educacional dessas instituições mantêm uma relação bastante direta com a concepção de infância e com a classe social à qual se destina a instituição.

Conforme aponta Campos (1996), a educação infantil nasceu da necessidade da mãe trabalhadora. Assim concebida, cabia à instituição "cuidar” das crianças pequenas, sendo o essencial mantê-las limpas, seguras e alimentadas. As pessoas que se encarregavam desses cuidados eram, em geral, mulheres consideradas naturalmente dotadas de habilidades para exercer essa função.

Abramowicz (2003) relata que a educação infantil tem passado por um momento fundamental: o processo de universalização dessa etapa da educação básica, que tem sido conquistada a partir das lutas da sociedade civil organizada em fóruns, das lutas das mulheres, dos partidos populares, etc. Entretanto, a qualidade não deve estar dissociada da universalização.

Para melhor compreender o percurso da educação infantil, trazemos um breve histórico da educação destinada à pequena infância. Sabemos que muitos foram os feitos e avanços, mas quais foram os conflitos, barreiras e conquistas dessa modalidade na sua trajetória histórica? Quais são as relações que se estabelecem entre os educadores e educadoras das instituições de educação infantil e qual a repercussão dessas relações na educação das crianças pequenas? Quais são os conflitos, barreiras e conquistas das relações de gênero na educação infantil?

Para responder a tais questionamentos, documentos e leis importantes foram analisados neste trabalho: a Constituição Federal de 1988; o Estatuto da Criança e do Adolescente, de 1990; a Lei de Diretrizes e Bases da Educação Nacional 9.394, de 1996; os Referenciais Curriculares Nacionais para a Educação Infantil, de 1998 e as Diretrizes Curriculares Nacionais para a Educação Infantil, de 1998.

A seguir apresentamos o histórico da educação destinada à pequena infância, a educação infantil - um direito e uma conquista, a síntese da análise documental e, a título de considerações, creche - um encontro com a realidade. 
A educação infantil em nosso país vem se expandindo e ganhando expressão. Tem buscado superar o enfoque meramente assistencialista que predominou por muito tempo na sua história, procurando rever o caráter compensatório e de paternalismo que tinha com as crianças de baixa renda.

A reivindicação para educação da criança pequena ganhou relevância no Brasil na segunda metade da década de 1970, principalmente pelos movimentos de mulheres feministas e comunitários. Nos anos 1980, diferentes setores da sociedade civil já participavam da mobilização de opinião pública para que uma nova Constituição Brasileira reconhecesse a educação das crianças pequenas como direito.

Na década de 1970, as políticas públicas de educação voltadas às crianças de 0 a 6 anos sustentaram-se na educação compulsória para supostas carências que traziam as crianças das camadas populares. Documentos oficiais do Ministério da Educação e do Desporto (MEC) e do Conselho Nacional de Educação (CNE) defendiam a ideia de antecipação de conteúdos da pré-escola para a resolução dos problemas do 1 ํㅡ grau.

Antes da Constituição Federal de 1988, a educação da criança pequena era pouco expressiva na legislação educacional e não se configurava como nível de educação. Após mais de uma década de debates e disputas políticas, o Congresso aprovou a Lei de Diretrizes e Bases 4.024/61; seu texto trazia que a criança pequena deveria receber educação apropriada. A LDB 4.024/61 dedicava apenas dois artigos à educação pré-primária, determinando que ela deveria ser destinada às crianças menores de 7 anos e ministrada em escolas maternais e jardins de infância (Art. 23). Determinava também que as empresas que empregassem mulheres com filhos menores de 7 anos seriam estimuladas a manter instituições pré-primárias em cooperação com o poder público, de acordo com o Art. 24.

Em 1971, em meio às dificuldades provocadas pela ditadura, a Lei 5.692/71 retirou dos governos quaisquer obrigações escolares relacionadas às crianças pequenas, estabelecendo que apenas os sistemas de ensino deveriam velar para que as crianças de idade inferior a 7 anos recebessem conveniente educação em escolas maternais, jardins de infância e instituições equivalentes (Art. 19). 
Campos (1999) aponta que:

A LDB 5692/71 - após intensos debates públicos dedica somente uma frase ambígua à educação das crianças menores de sete anos. Porém cada vez em maior número as famílias encaminham suas crianças entre 0 e 6 anos a uma multiplicidade de formas de atendimento oferecidos por inúmeros programas instituídos por diferentes órgãos públicos, convênios com entidades filantrópicas e comunitárias, e também a todo tipo de escolinhas - sem nenhuma fiscalização pública (p.121).

Felizmente, na década de 1980, avanços no campo teórico começaram a alterar a educação voltada às crianças de 0 a 6 anos. A própria expressão educação infantil foi adotada recentemente na legislação vigente em nosso país para caracterizar as instituições educacionais de atendimento das crianças de 0 a 6 anos de idade, conforme afirma Kuhlmann Junior (1998).

Durante muito tempo, a educação das crianças pequenas foi considerada responsabilidade de suas famílias ou dos grupos sociais nos quais elas viviam. Por um longo período não existiu nenhuma instituição destinada aos cuidados e à educação dos meninos e meninas pequenos. Portanto, a educação infantil como conhecemos hoje, após a LDB 9.394/96, com responsabilidade complementar à ação da família, é bastante recente.

As creches e pré-escolas surgiram a partir das mudanças econômicas, políticas e sociais que ocorreram na sociedade. Pela incorporação da mulher ao trabalho assalariado, houve uma reorganização das famílias. Assim, homens e mulheres passaram também a assumir novos papéis na relação entre os sexos. Conforme Haddad (2002):

\section{[...] A participação mais intensa e efetiva da mulher na vida econômica, política e social e a significativa ampliação do papel da mãe nos diferentes grupos familiares, exigem, por sua vez, uma revisão de suas tradicionais atribuições no espaço doméstico, assim como a redefinição do papel masculino na reprodução e no cuidado com os filhos (HADDAD, 2002, p. 92).}

Essa ampliação também foi possível porque a sociedade modificou a sua maneira de pensar sobre o que é ser criança e quais são as suas necessidades e saberes. Alguns autores, como Ariès (1981), instalaram a discussão sobre o surgimento do "sentimento da infância". Segundo ele, essa categoria foi entendida a partir de dois sentimentos: primeiro, a paparicação - a criança, por sua ingenuidade, gentileza e graça, era uma fonte de distração para o adulto; e segundo, pela moralização - pois os adultos tinham como objetivo principal formar homens e mulheres racionais e cristãos para atuarem na sociedade. 
As instituições destinadas aos cuidados das crianças pequenas surgiram na Europa, na metade do século XIX. Essas instituições começaram a crescer quando parte desse continente se industrializou, provocando como consequência o aparecimento de grandes cidades. Muitas das instituições criadas para cuidar da pequena infância surgiram motivadas pelo fato de as mães terem sido deslocadas para o trabalho assalariado com a Revolução Industrial.

Desse modo, o surgimento das instituições para o cuidado das crianças pequenas teve no seu início um objetivo assistencialista. Seus enfoques eram a guarda, a higiene, a alimentação e os cuidados físicos das crianças pequenas. Conforme afirma Bujes ${ }^{1}$ (apud CRAIDY; KAERCHER, 2001, p. 15):

[...] muitas teorias nesta época também estavam interessadas em descrever as crianças, na sua natureza moral, suas inclinações boas ou más. Defendiam ideias de que proporcionar educação era, em alguns casos, uma forma de proteger a criança das influências negativas do seu meio e preservar-lhes a inocência; em outros, era preciso afastar a criança da ameaça de exploração; em outros, ainda, a educação dada às crianças pequenas tinha por objetivo eliminar as inclinações para a preguiça, a vagabundagem, que eram consideradas características das crianças pobres (BUJES, apud CRAIDY; KRAECHER, 2001, p. 15).

Ao longo da história da educação, as poucas conquistas não se fizeram sem conflitos. Com o avanço da industrialização e o acréscimo na quantidade de mulheres no mercado de trabalho, aumentou também a demanda pelos serviços das instituições de atendimento à pequena infância.

No âmbito dos movimentos sociais, a demanda por creche era vista na perspectiva do direito da mãe trabalhadora. Em outro espaço de mobilização, os movimentos eram pela defesa dos direitos das crianças e adolescentes, que lutavam principalmente pelo atendimento das crianças de famílias em situações de risco.

Conforme apontado anteriormente, no final da década de 1970 e na década de 1980, as diferentes mobilizações da sociedade civil foram marcantes para a educação das crianças pequenas - elas demandavam a extensão do direito à educação para as crianças pequenas. Os movimentos feministas que partiram dos Estados Unidos tiveram um papel importante e especial na revisão das instituições de atendimento à criança pequena. As feministas mudaram o seu enfoque: no início, consideravam a creche como um programa social para as mães trabalhadoras pobres, mas posteriormente passaram a defender a ideia

BUJES, Maria Isabel Edelweiss. Escola infantil: pra que te quero? In: CRAIDY, Carmem; KAERCHER, Gladis. Educação infantil: pra que te quero? Porto Alegre: Artmed, 2001. p. 13-22. 
da educação como um direito de todas as crianças.

Sendo assim, a educação infantil deixou de ser considerada como um conjunto de instituições caritativas e filantrópicas, para ser aclamada como a primeira etapa da educação básica e de aprendizagem ao longo da vida.

Didonet (2007) aponta que o espaço que a educação infantil ocupa hoje na legislação e na política educacional não é resultado de uma evolução natural dos sistemas de ensino. Ela é conquista persistente, de sólida argumentação, com intensa mobilização e pressão social.

As creches no seu início foram criadas em sua maioria para atender as crianças de 0 a 6 anos de idade em período integral, vinculando-se aos sistemas de bemestar social e políticas assistencialistas e compensatórias. Já as pré-escolas foram criadas dentro do sistema educacional para o atendimento de crianças entre 4 e 6 anos de idade, tendo seu funcionamento em período parcial com o propósito de preparar as crianças para o processo de escolarização.

A incorporação das creches e pré-escolas ao sistema educacional não necessariamente tem proporcionado a superação da concepção assistencialista, conforme aponta Bujes² (apud CRAIDY; KAERCHER, 2001):

A experiência educativa que percorre as creches e pré-escolas tem variado bastante. Quando se trata de crianças das classes populares, muitas vezes a prática tem se voltado para as atividades que têm por objetivo educar para submissão, o disciplinamento, o silêncio, a obediência. De outro lado, mas de forma igualmente perversa, também ocorrem experiências voltadas para a escolarização precoce, igualmente disciplinadoras, no seu pior sentido (BUJES, apud CRAIDY; KAERCHER, 2001, p.16).

Assim, a origem dessas instituições, baseada em sistemas diferenciados, de assistência e educação, demarcou uma diferença notória no funcionamento das creches e pré-escolas no Brasil. Entretanto, estudiosos da área, como Maria Malta Campos (1996, 1999), Fúlvia Rosemberg e Maria Malta Campos (1995), Anete Abramowicz e Gisela Wajskop (1999) e Anete Abramowicz (2003), trazem com convicção que esta dualidade assistência-educação é explicada a partir da intencionalidade de cada espaço, pois algumas creches traziam e ainda trazem no seu projeto educativo uma educação voltada para a população pobre, enquanto a pré-escola, por sua vez, fora e é entendida como uma instituição preparatória para a escolarização obrigatória.

BUJES, Maria Isabel Edelweiss. Escola infantil: pra que te quero? In: CRAIDY, Carmem; KAERCHER, Gladis. Educação infantil: pra que te quero? Porto Alegre: Artmed, 2001. p. $13-22$. 
Entendemos, portanto, que a educação da criança pequena envolve simultaneamente dois processos complementares e indissociáveis: o educar e o cuidar. As crianças dessa faixa etária têm necessidades de carinho, atenção, afeto, segurança e, simultaneamente, tomam contato com o mundo por meio das experiências com as pessoas, com as diferentes formas de expressão e com as coisas que existem em sua realidade. Assim, a educação infantil deve primar pelo desenvolvimento das múltiplas dimensões humanas durante a primeira infância. Creches e pré-escolas precisam ser espaços onde as crianças vivam interessantemente, satisfatoriamente e alegremente as suas experiências, tendo a possibilidade de explorar o mundo, fantasiar, brincar, ter contato com a natureza e acesso ao conhecimento.

\section{EDUCAÇÃO INFANTIL: UM DIREITO, UMA CONQUISTA!}

A Constituição Federal de 1988 reconheceu o direito próprio da criança pequena e a importância do ensino para essa faixa etária, permitindo que a criança da primeira infância pudesse ter assegurado um serviço e um atendimento de acordo com as suas necessidades humanas universais. $\mathrm{Na}$ segunda metade da década de 1980, movimentos sociais vinculados aos diferentes setores das políticas sociais se organizaram visando inserir 0 direito da criança na nova Carta Constitucional que seria elaborada. Com a educação infantil não foi diferente, pois vários segmentos uniram forças com o objetivo de sensibilizar a sociedade civil sobre a importância de compreender a infância e sua educação.

A educação infantil, que antes era um direito apenas dos filhos e filhas de mães trabalhadoras, passou a ser direito de todas as crianças com a Constituição Federal Brasileira de 1988. A responsabilidade de oferecer em creches e pré-escolas uma educação de qualidade para todos os meninos e meninas de famílias que desejassem ou necessitassem desses serviços foi delegada ao poder público municipal. Ainda de acordo com a Constituição Federal Brasileira, a educação da infância evidenciou os direitos e garantias fundamentais nos princípios de legalidade e de igualdade. Isso pode ser observado na Constituição, no Artigo 5, quando nela se afirma que "todos são iguais perante a lei, sem distinção de qualquer natureza" (p. 13).

Além dessas conquistas, a Constituição de 1988 manteve, como era esperado, o dispositivo que atribuía à União a competência para fixar as Diretrizes e Bases da Educação Nacional. A consequência disso foi o início do processo de elaboração da nova Lei de Diretrizes e Bases da Educação. 
De acordo com a Lei de Diretrizes e Bases Nacional 9.394, de 20 de dezembro de 1996, a educação infantil é definida como a primeira etapa da educação básica, juntamente com o ensino fundamental e o médio. Ou seja, a educação infantil é um nível de ensino no qual a criança tem direito ao seu desenvolvimento integral nos aspectos físico, psicológico, intelectual e social, complementando a ação da família e da comunidade, possibilitando, assim, a ampliação social ao integrá-la à formação comum para o exercício da cidadania.

Em pesquisas no âmbito das políticas públicas, a ampliação de vagas desta modalidade deveria ser uma das formas mais justas de garantir a sua oferta à população. Conforme Campos, Fullgraf e Wiggers (2006), o acesso da população brasileira às creches e pré-escolas ainda é relativamente baixo: apenas 57,1\% têm acesso à educação infantil e, destas crianças, apenas 10,6\% têm de 0 a 3 anos de idade. As autoras também afirmam que ainda há grandes desigualdades no acesso das crianças à creche e pré-escola, pois é mais alto o percentual de matrículas das crianças mais velhas, das famílias de renda média, cor branca, de pais com escolaridade mais alta, com mães que trabalham fora, de regiões mais desenvolvidas e nas zonas urbanas. Contrastando com esses dados, a LDB 9.394/96 traz na sua escrita que a educação infantil se destina a todas as crianças, sem distinção de gênero, cor, etnia, proveniência social, credo político ou religioso, com ou sem deficiência de qualquer natureza.

O aumento da demanda pela educação infantil expressa mudanças sociais acerca das concepções sobre as famílias, sobre a responsabilidade de homens e mulheres na educação dos seus filhos, proteção à infância, a participação da mulher no mercado de trabalho e na vida pública, levando, enfim, à redefinição dos papéis masculinos e femininos. Todo esse processo leva a modificações na estrutura familiar e na própria sociedade. Nessas concepções, a criança é reconhecida como um ser social, portadora de direitos e de necessidades específicas para o seu desenvolvimento social, físico, emocional e intelectual.

A educação infantil é um território de atuação na sua maioria realizado por mulheres, e discutir as relações de gênero nesta modalidade de ensino é uma forma de indicar que não é só porque há muitas mulheres na escola que a profissão é feminina. É de extrema importância avançar na compreensão de que não são os conhecimentos ditos femininos, naturais, o gostar de criança e a vocação que qualificam as práticas das educadoras, mas a busca por novos conhecimentos que superem o trabalho assistencialista, apontando assim para o início de uma profissionalização docente, com intencionalidade educativa. 
Para firmar e completar este pensamento, Haddad (2006) afirma que nas escolas de educação infantil deve haver profissionais de ambos os sexos, qualificados e bem remunerados, que preencham as funções sociais e educacionais, deixando de lado a ideia de que a educação e o cuidado são apenas domínio das mulheres e que não requerem habilidades profissionais.

A partir da LDB 9.394/96 e do Referencial Curricular Nacional para a Educação Infantil, das Diretrizes Curriculares Nacionais para a Educação Infantil (1998, 1999), as políticas públicas deveriam tomar caminhos menos nebulosos e mais definidos no que diz respeito à formação dos educadores e educadoras da primeira infância, à expansão de vagas e à necessidade de uma política educacional para o atendimento pedagógico da criança pequena, mas sabemos que essas ainda são conquistas a serem alcançadas.

Foi no final da década de 1990 que o Ministério da Educação e do Desporto (MEC) distribuiu às escolas de educação infantil de todo o país o documento Referencial Curricular Nacional para a Educação Infantil - RCNEl. Buscavase auxiliar os educadores e educadoras na realização diária do seu trabalho educativo junto às crianças, apontando metas de qualidade para garantir o desenvolvimento integral das crianças, reconhecendo, assim, o seu direito à infância como parte dos seus direitos de cidadania.

O RCNEI foi comentado e estudado por inúmeros pesquisadores, que evidenciaram muitas críticas. Entre esses estudiosos, encontram-se Ana Beatriz Cerisara (2002) e Lenira Haddad (2002). Contudo, vale ressaltar que este documento se constituiu como uma primeira proposta curricular oficial destinada à educação infantil, tanto para as creches como para as pré-escolas.

Nos anos de 1998 e 1999, após a publicação do RCNEI, o Conselho Nacional de Educação (CNE) aprovou as Diretrizes Curriculares Nacionais para a Educação Infantil (BRASIL, 1998), que tinham como objetivo direcionar, de modo obrigatório, os encaminhamentos de ordem pedagógica para esta modalidade de ensino aos sistemas municipais e estaduais de educação. Também foram aprovadas as diretrizes curriculares para a formação de professores da educação infantil e do ensino fundamental, buscando contribuir para a melhoria do ensino ao discutir a relevância de uma formação qualificada para os professores.

Diversos autores trazem nas suas publicações a importância de defender uma perspectiva de que a criança precisa estar em primeiro plano, e não em um contexto de fundo para as políticas educacionais da educação infantil. 
O reconhecimento de que a criança pequena é cidadã, um ser competente, exigente e que deve receber uma educação de qualidade é primordial para a garantia dos seus direitos fundamentais, como denunciaram Rosemberg e Campos (1995, p. 155), pois a desigualdade apresenta diversas faces. Esta não se resume apenas às diferenças sociais e econômicas, mas se expressa também nas discriminações de etnia e de gênero.

Após a denúncia da autora, o MEC publicou, em 1995, o documento intitulado Os critérios de atendimento de uma creche que respeita os direitos fundamentais da criança, de autoria de Maria Malta Campos e Fúlvia Rosemberg. Esse foi um marco para a educação infantil brasileira e a obra se tornou uma referência clássica para a área. Nela, doze critérios buscavam garantir a todas as meninas e meninos que frequentavam as escolas e espaços coletivos de educação infantil as condições mínimas para construir e viver a sua infância.

As autoras reforçaram a concepção de creche como um lugar de educação infantil, no qual o foco está na criança e em seu desenvolvimento, articulando o cuidar (atenção, aconchego, higiene, saúde e alimentação) e o educar (estímulo, desenvolvimento da curiosidade, imaginação, capacidade de expressão) na perspectiva do desenvolvimento pleno, conforme a legislação vigente.

Outros documentos importantes para a modalidade foram os Parâmetros Nacionais de Qualidade para a Educação Infantil (MEC/SEF, 2006) e os Indicadores de Qualidade da Educação Infantil (MEC/SEB, 2009). Esses documentos trouxeram na sua escrita que é imprescindivel levar em conta que as crianças, desde que nascem, são: cidadãos de direitos, indivíduos únicos e singulares, seres sociais e históricos, competentes e produtores de cultura. $E$ que, por isso, precisam ser apoiados e incentivados a brincar, a movimentarse, a expressar sentimentos e pensamentos, a desenvolver a sua imaginação e curiosidade. Assim se objetiva ampliar os seus conhecimentos a respeito do mundo, da natureza e da cultura, proporcionando às crianças diversidade nas escolhas e oportunidade de eleger seus companheiros de interação.

Kuhlmann Junior (1998) também reforça que não basta apenas transferir as creches para os sistemas de ensino, pois, na sua história, as instituições de educação infantil destinavam às crianças pequenas uma educação de baixa qualidade, e é isso que precisa ser superado e transformado nas atuais escolas da primeira infância. 


\section{SÍNTESE DA ANÁLISE DOCUMENTAL}

Avaliamos que os documentos aqui estudados e apresentados relatam timidamente a importância do trabalho e do olhar para a educação infantil sob a ótica de gênero. Buscam deixar nas suas escritas que no ambiente educacional meninos e meninas devem ser tratados igualmente e encorajados pelos seus educadores e educadoras, mas a importância de essas questões estarem explícitas, claras e com objetividade nas escritas desses documentos são de fundamental importância para a organização do trabalho pedagógico. Ensinar a respeitar o diferente, a desfrutar da riqueza que a variedade e a diversidade nos oferecem, na verdade, são formas de combater a desigualdade, a discriminação e a submissão. Portanto, são ações urgentes e necessárias.

Sabemos, contudo, que o país é marcado por diferenças, e o equilíbrio entre a preocupação com a igualdade e a preocupação com o respeito às diferenças nem sempre é fácil de alcançar, pois o desigual acesso à renda e aos programas sociais está marcado por pertencimentos de classe, de etnia, de gênero, heranças históricas e culturais que também se expressam no acesso à educação infantil e na qualidade oferecida.

Como marcos recentes e conquistas da história da educação infantil sob a ótica de gênero, apontamos:

- Que a educação da criança pequena passou a ser um direito, portanto, todos os meninos e meninas de 0 a 6 anos de idade têm o direito à educação infantil com qualidade.

- Os pais, já não apenas mulheres-mães, passaram a ter direitos como trabalhadores, bem como à educação de seus filhos e dependentes.

- Que organizações sociais estão atuantes na busca por uma educação infantil de qualidade por meio de seminários, fóruns, encontros e congressos, bem como por meio das produções acadêmicas realizadas.

Também apontamos que ainda há barreiras a serem superadas, como:

- As creches ainda abrigam uma diversidade de modelos de atenção, muitas destes de péssima qualidade, e que ainda estão associados à criança pobre, a uma ação assistencialista, à prestação de cuidados físicos, de saúde e alimentação. A pré-escola, no entanto, ainda está associada à preparação para o ensino fundamental.

As instituições educativas, contudo, são entendidas como espaços de garantia de direitos. Mas, para tanto, é fundamental atentar para as demandas da sociedade, entendendo-as como parâmetros para o desenvolvimento 
das atividades educacionais. Na defesa de uma educação pública, gratuita, democrática, de qualidade e para todos, a universalização do acesso e a garantia da permanência para meninos e meninas na educação infantil é um desafio. Da mesma forma se constitui um desafio à superação das desigualdades que proporcione o respeito à diversidade.

Conforme afirma Lima (2007), a escola cumpre com um objetivo antropológico muito importante: "garantir a continuação da espécie, socializando para as novas gerações as aquisições e invenções resultantes do desenvolvimento cultural da humanidade" (2007, p. 6). E isso se inicia na infância, nas escolas de educação infantil. Barbosa (2009) afirma que o encontro entre adultos e crianças na escola é extremamente importante para que as crianças possam ter conhecimento de si, do outro e da sua realidade.

O que se espera de uma instituição da primeira infância é que ela possa acolher para educar e cuidar, compartilhando com as famílias o processo de formação e constituição da criança pequena em sua integridade; que a escola tenha uma função política de contribuir para que meninos e meninas usufruam direitos sociais, políticos e exerçam seu direito de participação; bem como exerça a função pedagógica de ser um lugar privilegiado de convivência e ampliação de saberes e conhecimentos de diferentes naturezas entre crianças e adultos que lá estão.

\section{CRECHE: UM ENCONTRO COM A REALIDADE}

A creche é hoje um espaço onde as crianças e os adultos passam sistematicamente horas dos dias juntos. Nessa convivência, crianças, educadores e educadoras, famílias e gestores, em um contexto de diferentes interações humanas, vivenciam a diversidade, as diferenças e suas experiências próprias.

Cada instituição se constrói e se reconstrói diariamente, a partir dos elementos humanos, espaciais, sociais, culturais e econômicos de que dispõe. Estudos teóricos e práticas deveriam orientar a elaboração das situações de aprendizagens que irão acontecer junto com as crianças. Também é necessário um projeto político-pedagógico que tenha como tarefa fundamental aproximar de forma reflexiva e crítica a utopia da comunidade escolar das dificuldades de seu cotidiano concreto, possibilitando avanços e constituindo uma educação capaz de formar seres humanos como autores de uma sociedade mais justa e solidária, conforme afirma Santos Neto (1999). 
Pensando a creche como um espaço de direito, de inventividade, de experiência e de imaginação, trazemos Bujes ${ }^{3}$ (apud CRAIDY; KAERCHER, 2001) para firmar nossas concepções, mesmo que sejam sempre provisórias:

Tudo isso leva-me a pensar que a experiência da educação infantil precisa ser muito qualificada. Ela deve incluir o acolhimento, a segurança, o lugar para a emoção, para o gosto, para o desenvolvimento da sensibilidade; não pode deixar de lado o desenvolvimento das habilidades sociais, nem o domínio do espaço e do corpo e das modalidades expressivas; deve privilegiar o lugar da curiosidade e o desafio a oportunidade de investigação (BUJES, apud CRAIDY; KAERCHER, 2001, p. 19).

A história da educação infantil no Brasil nos aponta que lentamente as instituições dessa modalidade estão procurando adequar o seu trabalho e a formação dos seus educadores e educadoras. Estão, dessa maneira, voltando-se para uma educação que possa contribuir para a construção de uma sociedade mais democrática, uma escola pública de qualidade, que tenha o compromisso com a justiça social e que busque, assim, transformar.

A creche ainda tem mostrado que há uma imensa distância entre o que é produzido sobre a educação da primeira infância e a escola real, principalmente quando falamos e tratamos sobre as diferenças sociais, econômicas e étnicas. Isso ainda é uma barreira a ser superada.

Aproximar-nos das ações e dos comportamentos que tomamos como naturais exige motivações a novos estudos e reflexões no combate às diferenças. É um desafio que nos compete e nos convoca.

Afinal, vivemos em um mundo em constante transformação e diversidade, cabendo às escolas de educação infantil uma leitura atenta do que está à sua volta. É importante salientar, no entanto, que as instituições, embora abriguem a imensa maioria de mulheres como educadoras, são espaços em que masculinidade e feminilidade interagem e compartilham experiências constantemente. Cabe identificarmos no cotidiano como elas se constituem, hierarquizam, cristalizam, entram em conflito ou se complementam.

BUJES, Maria Isabel Edelweiss. Escola infantil: pra que te quero? In: CRAIDY, Carmem; KAERCHER, Gladis. Educação infantil: pra que te quero? Porto Alegre: Artmed, 2001. p. 13-22. 


\section{Conflicts, obstacles, and achievements of gender relations in infant education}

Abstract: This paper discusses the historical background of early childhood education in the main laws and documents that guide the Brazilian education from the perspective of gender. Many are the conflicts and barriers of early childhood education, but over the years several achievements have been achieved in terms of gender relations in this type of education. Organizing interaction among pairs within the early childhood institutions is a form to make opportunity of the most varied understandings of themselves, each other and reality.

Keywords: Early Childhood education. Gender relations. Teacher education. 


\section{REFERÊNCIAS}

ABRAMOWICZ, Anete. $O$ direito das crianças à educação infantil. Pro-posições, São Paulo, v. 14, n. 3, p. 13-24, 2003.

; WAJSKOP, Gisela. Educação infantil: creches - atividades para crianças de zero a seis anos. São Paulo: Moderna, 1999.

ARIÉS, Philippe. História social da criança e da família. Rio de Janeiro: Livros Técnicos e Científicos, 1981.

BARBOSA, Maria Carmem Silveira. Práticas cotidianas na educação infantil bases para a reflexão sobre as orientações curriculares. Brasília: MEC/SEB, 2009.

BRASIL. Constituição da República Federativa do Brasil. Lei Federal de 05/10/1988. Brasília: Senado Federal, 2000.

CNE, CEB. Diretrizes Curriculares Nacionais para a Educação Infantil. Parecer no 22/98, aprovado em 17 de dezembro de 1998.

. Estatuto da Criança e do Adolescente. Organização dos textos, notas e índices por Juarez de Oliveira. 6. ed. Atualizada e ampliada. São Paulo: Saraiva, 1996.

. Indicadores de Qualidade na Educação Infantil. Brasília: MEC/SEB, 2009.

. Presidência da República, Casa Civil. Lei de Diretrizes e Bases da Educação Nacional. Lei 9.394 de 20 de dezembro de 1996. Brasília, 1996.

- Ministério da Educação. Parâmetros de Qualidade da Educação Infantil. V. I e II. Brasília: MEC/SEF, 2006.

- Ministério da Educação. Referencial Curricular para a Educação Infantil. V. I, II e III. Brasília: MEC/SEF, 1998.

BUJES, Maria Isabel Edelweiss. Escola infantil: pra que te quero? In: CRAIDY, Carmem; KAERCHER, Gladis. Educação infantil: pra que te quero? Porto Alegre: Artmed, 2001, p. 13-22.

CAMPOS, Maria Malta. A formação de professores para crianças de 0 a 10 anos: modelos em debate. Educação e Sociedade, São Paulo, n. 68, p. 126142, 1999. 
- A mulher, a criança e seus direitos. Cadernos de Pesquisa, São Paulo, n. 106, p. 117-127, 1996.

; FULLGRAF, Jodete; WIGGERS, Verena. A qualidade da educação infantil brasileira: alguns resultados de pesquisas. Cadernos de Pesquisa, São Paulo, v. 127, n. 36, p. 87-128, 2006.

; ROSEMBERG, Fúlvia. Critérios para um atendimento em creches que respeite os direitos fundamentais das crianças. Brasília: MEC, SEB, 1995.

CERISARA, Ana Beatriz. O Referencial Curricular Nacional para a educação infantil no contexto das reformas. Educação e Sociedade, São Paulo, v. 23, n. 80, p. 326-345, set. 2002.

DIDONET, Vital. Fragmentos de histórias da educação infantil no Brasil: algumas reflexões. Revista Virtual de Gestão de Iniciativas Sociais, Rio de Janeiro, n. 11, p. 44-52, jun. 2007.

HADDAD, Lenira. A creche em busca de sua identidade: perspectiva e conflitos na construção de um projeto educativo. 3. ed. São Paulo: Loyola, 1993.

Políticas integradas de educação e cuidado infantil: desafios, armadilhas e possibilidades. Cadernos de Pesquisa, São Paulo, v. 36, n. 129, p.519-546, 2006.

KUHLMANN JUNIOR, Moysés. Infância e educação infantil: uma abordagem histórica. 4. ed. Porto Alegre: Mediação, 1998.

LIMA, Elvira Souza. Currículo, cultura e conhecimento. São Paulo: Inter Alia, 2007.

ROSEMBERG, Fúlvia; CAMPOS, Maria Malta. Creches e pré-escolas no hemisfério norte. São Paulo: Cortez, 1994.

SANTOS NETO, Elydio dos. O projeto político pedagógico da escola: caminhos para a organização do trabalho coletivo. Revista Ciências da Educação, Lorena: v. 1, n. 1, p. 81-85, 1999.

RECEBIDO: Junho de 2014.

APROVADO: Outubro de 2014. 